\title{
ICU and non-ICU cost per day
}

Colleen Norris MN, ${ }^{*}$ Philip Jacobs PhD CMA, † John Rapoport PhD,§ Stewart Hamilton MD $\dagger$
The purpose of this study was to compare the cost of a day spent in an intensive care unit and a day spent on a general nursing unit. A descriptive design was used, based on patient level data, to examine and compare unit costs per day for each of the ICU and non-ICU portions of a patient's hospital stay. Records from 386 patients who were treated in a general medical/surgical ICU were analyzed. Records for patients who received both ICU and non-ICU care during their stay were retained. Patients were categorized according to whether they had received surgical care prior to admission to the ICU (surgical group) or had no surgical care (medical group). The groups were further divided, based on whether they were discharged from hospital (survivors), or died following transfers from the ICU (non-survivors). All four groups; surgical or medical, survivors and non-survivors, were analyzed separately. The ICU direct costs per day for survivors were between six and seven times those for non-ICU care. A one day substitution of general ward for ICU care would result in a cost reduction of $\$ 1,200$ per patient for survivors. The results suggest that the savings achieved by moving a patient from ICU to non-ICU care are considerable, particularly for less severe surviving patients. In making such decisions, however, clinicians must examine prospective benefits as well as costs. If the health outcomes are not influenced, the savings from substitution are considerable, and there is a strong economic argument for substitution.

Ce travail vise à comparer les coûts quotidiens de lhospitalisation en unité de soins intensif (USI) à ceux de l'unité de soins réguliers. Un modèle basé sur l'observation des données spécifiques au patient est utilisé pour examiner et comparer les coûts quotidiens de chacune des périodes de séjour hos-

\section{Key words}

INTENSIVE CARE:

COSTS.

From the *Approach Project, University of Calgary, †Faculty of Medicine, University of Alberta, $\ddagger$ Health Economics Research Centre, Royal Alexandra Hospital, Edmonton, §Mount Holyoke College, South Hadley, Massachusetts. Address correspondence to: Dr. Philip Jacobs, Department of Public Health Sciences, 13-103 Clinical Sciences Building, University of Alberta, Edmonton, Alberta, Canada T6G 2 G3. Accepted for publication 6th November, 1994. pitalier dans l'USI et à l'extérieur de l'USI. Les dossiers de 386 patients traités dans une unité de soins intensifs médicochirurgicaux sont analysés. Seuls les dossiers de ceux qui ont reçu des soins à l'USI et hors de l'USI sont retenus. Deux catégories de patients sont établies; ceux qui ont reçu des soins chirurgicaux avant leur admission à l'USI (groupe chirurgical) et ceux qui n'ont pas reçu de soins chirurgicaux (groupe médical) avant leur admission à l'USI. Ces groupes ont été subdivisés: ceux qui ont reçu leur congé de l'hôpital (survivants) et ceux qui sont décédés après leur transfert de l'USI (décédés). Les quatre groupes: chirurgical, médical, survivant, décédé sont analysés indépendamment. Les coût directs par journée de séjour à l'USI par survivant se situent entre six et sept fois ceux du séjour hors USI. La substitution d'une journée d'USI pour une journée de séjour en unité régulière permet une économie de $1200 \$$ par survivant. Ces résultats permettent de croire que les économies réalisées en transférant un malade de l'USI vers une unité régulière sont importantes, particulièrement pour les survivants les moins malades. Cependant, en prenant de telles décisions, les cliniciens doivent tenir compte autant des bénéfices que des coûts. Si la substitution ne compromet pas le pronostic, les économies réalisées sont considérables et il devient impérieux d'adhérer à cette pratique.

There have been a number of studies ${ }^{1-9}$ of ICU costs, several of which have focused on the ratio of the cost of ICU care to non-ICU care, ${ }^{1,2}$ but none have directly addressed the issue of substitutability. Two studies, whose purpose was to determine the national cost of ICU care, estimated the ratio of ICU to non-ICU costs per day based on averages of costs of all patients in each treatment venue, regardless of patient type and severity. These studies did not use patient-specific cost data and the resulting ratio of ICU to non-ICU cost per day was estimated at $3: 1$ 1,2 $^{1,2}$

There have been studies of the cost of patients who were in the ICU at some portion of their stay, that examined patient costs individually. In general, these studies have either focused exclusively on the costs of the ICU portion of a stay, ${ }^{3-9}$ or on the total hospital stay. ${ }^{10-13}$ Only one analysis ${ }^{14}$ has examined resource use for both the ICU and non-ICU portions of the stays. The authors used patient charges rather than costs, and focused on two specific groups - brain surgery and coronary artery bypass surgery. They concluded that the costs for the 
ICU portion of the stay were 3.8 times that for the nonICU portion. However, the issues of substitutability and marginal costs were not addressed. Two studies have been conducted in Canada. ${ }^{3,7}$ Both focused only on the ICU portion of the stay, and only one examined patient specific costs. $^{3}$

The University of Alberta Hospitals Patient Resource Consumption Profile (PRCP) is a data base that contains patient-specific costs with daily detail. The data were used to estimate the cost per day of Intensive Care Unit (ICU) patient care and post-ICU care, for patients who had received both. The purpose was to determine the comparative costs of these potentially substitutable services: one full ICU day and one full ward day. This would allow one to estimate the savings in resources by shifting a day of ICU care to non-ICU care.

The study was designed to address the issue of ICU and non-ICU costs for individual patients who had received both ICU and non-ICU services during their stay. Average direct daily costs (both for ICU and non-ICU portions) were derived. These cost measures can be used as an approximation for marginal cost, in order to examine the economic issues related to substitutability.

\section{Methods}

The costing purpose was to determine costs of substitutable services, defined as one ICU day and one nonICU day. Direct costs, incurred in the relevant cost centres and which exclude indirect overhead such as administration and general depreciation, were used. The bulk of these costs were for labour and materials, and were treated as variable cost. Operating room costs were excluded as these were one-time costs, which did not occur daily. Marginal costs, the costs of one additional day of care, were assumed to be equal to average variable cost per day. Using this assumption, we based our estimates of marginal cost on the average per diem cost of each type of care.

\section{Setting}

The study setting was the University of Alberta Hospital, an 805-bed, teaching acute care hospital. The ICU studied is a nine-bed unit which admits a variety of adult patients, excluding neurosurgery, cardiac surgery, coronary care and burn patients. The Patient Resource Consumption Profile (PRCP) applies standard costs to utilization statistics. ${ }^{15}$ Several real-time automated feeder systems contribute patient-specific diagnostic and therapeutic data to the PRCP database: Diagnostic Imaging, Laboratory, Inpatient Nursing Acuity measures, Surgical Suite procedures (inpatient), Day Surgery procedures (outpatient), Rehabilitation services, and Patient Discharge Abstracting. The details of what specific services were provided, by whom and when, are linked to the ICD-9-CM diagnosis codes and grouped for case mix assignment. These data are further qualified by the method and/or location of service provision. For example, a chest $x$-ray could be provided in a standard location, on a mobile basis, in the Operating Room, or on a child/adult patient. Each of such methods can potentially generate a different cost and is tracked, and costed, accordingly. Those elements of the PRCP costs which were used in this study are described below. Excluded from the study are surgical suite costs (usually one-time costs occurring at the beginning of a stay) and pharmaceutical costs (not available).

The Diagnostic Imaging costing component allocates all of the Diagnostic Imaging departmental expenditures across patient-specific examination volumes. Costs related to labour included those of technicians, interpretation fees, clerical staff, records processing, diagnostic imaging specific nurses and any other staff categories within the department (except management, which were included as department overhead costs). Material costs were limited to departmental overhead; they excluded items such as housekeeping and plant operational costs which were not charged to the Diagnostic Imaging department.

The Laboratory costing component included all departmental labour costs (except medical staff salaries, management staff which are included as overhead, and research and education-related staff) allocated on the basis of NHPIP units, supplemented by a divisional labour cost per unit. Material costs included all such items from med/surg supplies, reagents, and drugs through to indirect expenditures such as contract maintenance, and minor capital equipment.

Nursing costs comprised labour, material and overhead portions. Both direct nursing care (based on a modification of the Medicus acuity classification system) and indirect labour such as unit clerks and other support staff were included. All materials, excluding drugs, that are attributed to the nursing units as well as unit-specific overhead costs including nurse managers and other administrative costs were incorporated into the nursing component. There are six levels of nursing; for the lower five levels, assignment to a class is determined by the Medicus scoring system. Daily weights are assigned to cases, by class, and daily ward costs as assigned to each patient based on its proportion of total ward weights. The sixth nursing level is for one-on-one nursing; for these cases costing was based on the actual time the patient received nursing care.

Rehabilitation services costs included labour, material, and overhead accrued within the areas of physiotherapy, occupational therapy, speech and audiology, orthotics, and prosthetics. Again, all department-specific expend- 
itures were allocated on a patient-specific basis; facility overhead such as housekeeping and plant operations were not included.

\section{Sample}

A total of 382 consecutive admissions to a general medical/surgical ICU during the time period April 1, 1991 to March 31, 1992 were studied. Of these 382 eligible patients, the following exclusions were made: patients with multiple ICU admissions during the same hospitalization; patients who received general ward care prior to ICU admission; patients transferred to another hospital directly from the ICU; patients who died in the ICU; and patients with missing nursing cost data on any day of their stay. Thus, only patients with a single ICU and non-ICU encounter during their stay were included.

\section{Variables analyzed}

Dependent variables analyzed were cost per day for ICU and non-ICU portions of the stay. Independent variables, which were used as approximations for case type and severity, were: medical and surgical groupings; and discharge status from the hospital (dead or alive).

\section{Method of analysis}

Descriptive analyses were derived. Tables were utilized to reflect the demograhic data. The analysis then focused on cost per day; including means and standard deviations for ICU and non-ICU cost per day for each of the four groups identified (medical survivor and non-survivor and surgical survivor and non-survivor), and on the differences between daily ICU and non-ICU costs. Calculations were based on direct rather than total (direct plus allocated) cost per ICU day. Values for the medians, means, standard deviations, and $95 \%$ confidence intervals for means were calculated for each of these variables.

\section{Results}

Of the 382 total cases, 331 were included for further analysis (Table I) and their characteristics are presented in Table II.

The median ICU cost per day of survivors was $\$ 1,357$ for medical cases and \$1,501 for surgical cases. Respective cost per day values for non-ICU (ward) care were $\$ 232$ and $\$ 281$. Differences in cost per day were $\$ 1,152$ for medical survivors and $\$ 1,220$ for surgical survivors. The mean ratios of ICU to non-ICU cost per day for survivors were 6.2 for surgical cases and 7.2 for medical cases.

The $95 \%$ confidence intervals for the difference mean cost per day between ICU and non-ICU cost per day were $\$ 1,201$ and $\$ 1,356$ for surgical survivors, and $\$ 1,154$ and $\$ 1,294$ for medical survivors. Intervals for nonsurvivors were much larger (Table III).
TABLE I Sample selection

\begin{tabular}{lrr}
\hline Included & & 331 \\
Excluded & & \\
- Died in ICU & 29 & \\
- Transferred out & 5 & \\
- Ward pre-ICU & 10 & \\
- Missing data & 7 & $\overline{51}$ \\
- Total & & $\overline{382}$ \\
Total & & \\
\hline
\end{tabular}

TABLE II Characteristics of sample

\begin{tabular}{lrl}
\hline Variable & $n$ & $\%$ \\
\hline Sex & & \\
- Female & 196 & 59.2 \\
- Male & 135 & 40.8 \\
Age (yr) & 52 & \\
Medical - survivors & 156 & $47 \%$ \\
$\quad$ - non-survivors & 35 & $11 \%$ \\
Surgical - survivors & 132 & $40 \%$ \\
$\quad$ - non-survivors & 8 & $2 \%$ \\
\hline
\end{tabular}

\section{Discussion}

This study focused on the differences between direct costs per day between ICU and non-ICU portions of a patient's stay. The main findings of this study are that differences in ICU and non-ICU cost per day are roughly between $\$ 1,200$ and $\$ 1,300$ for surviving patients. Confidence intervals for non-surviving cases were much higher, due both to the high standard deviations and the low sample sizes for these cases.

This study is the first which provides a comparison of ICU with non-ICU costs for the specific purpose of examining the issue of substitutability of the last ICU day and the first non-ICU day. Unlike other studies, ${ }^{1,14}$ this analysis included ICU and non-ICU cost per day for the same patients, and contained same case type (medical surgical) and severity (survivors, non-survivors) controls. The results indicate that, for surviving patients, the ratio of ICU to non-ICU cost per day is between 6 and 7 to 1 ; other studies indicated a rate of about 3 to 1.1,2

The present study employed direct variable cost per day, which is a better measure of marginal cost than has been used in previous studies. First, one-time costs related to the operating room have been excluded, as these would have influenced our estimate of the cost of the last ICU day for surgical cases. Second, we have excluded allocated overhead costs. These costs would have added roughly $45 \%$ to direct costs, but would not have been affected by substitutions of ICU for non-ICU days of care. Third, it should also be noted that drug costs (about five percent of costs) were excluded from the analysis because the PRCP data set does not contain drug costs. 
TABLE III Cost per day statistics

\begin{tabular}{|c|c|c|c|c|c|}
\hline Variable and type of case & Median & Mean & $\begin{array}{l}\text { Standard } \\
\text { deviation }\end{array}$ & $\begin{array}{l}\text { Lower } \\
\text { confidence } \\
\text { interval }\end{array}$ & $\begin{array}{l}\text { Upper } \\
\text { confidence } \\
\text { interval }\end{array}$ \\
\hline \multicolumn{6}{|l|}{ ICU cost per day } \\
\hline Surgery - survivors & $\$ 1,501$ & $\$ 1,562$ & $\$ 450$ & $\$ 1,484$ & $\$ 1,639$ \\
\hline - non-survivors & 1,463 & 1,650 & 494 & 1,236 & 2,064 \\
\hline Medical - survivors & 1,357 & 1,468 & 454 & 1,396 & 1,540 \\
\hline - non-survivors & 1,502 & 2,234 & 2,832 & 1,260 & 3,207 \\
\hline \multicolumn{6}{|l|}{ Non-ICU cost per day } \\
\hline Surgery - survivors & 281 & 283 & 95 & 266 & 299 \\
\hline - non-survivors & 325 & 331 & 57 & 283 & 380 \\
\hline Medical - survivors & 232 & 243 & 108 & 226 & 260 \\
\hline - non-survivors & 250 & 282 & 141 & 233 & 331 \\
\hline \multicolumn{6}{|c|}{ Difference between ICU and non-ICU cost per day } \\
\hline Surgery - survivors & 1,220 & 1,279 & 451 & 1,201 & 1,356 \\
\hline - non-survivors & 1,095 & 1,318 & 520 & 882 & 1,754 \\
\hline Medical - survivors & 1,152 & 1,224 & 442 & 1,154 & 1,294 \\
\hline - non-survivors & 1,246 & 1,951 & 2,753 & 1,005 & 2,897 \\
\hline
\end{tabular}

However, the most expensive drugs used and the biggest portion of the pharmacy budget is accounted for by immunosuppressive medications (cyclosporine) and antibiotics. Both classes of drugs were used in the ICU and in the regular medical/surgical units. There were no oncology nor transplantation patients in our sample; these are patients whose ICU drug costs would most likely have exceeded non-ICU drug costs.

With regard to clinical implications of the findings of the study, it should be stressed that the study focused on the costs of substitution, and not the benefits. An examination of the benefits would include measures of the differences in health outcomes resulting from shifting (for at least less severe cases) ICU patients to non-ICU care. Both the benefits and the costs would have to enter such a discussion.

In summary, this study examined the direct per day costs of ICU and non-ICU care with a view to estimating the economic implications of substituting days of care. Data were collected on a case-by-case basis, and were sorted by case type and severity (survivorship). Due to the sample size and variability of costs, survivors were the focus of the analysis. The results indicated net savings which would arise from substitution were roughly $\$ 1,200$ per day for medical and surgical cases. This study did not examine health outcomes, and any decision relating to substitution should be made with regard to benefits (health outcomes) as well as costs.

\section{References}

1 Russell LB. Technology in Hospitals: Medical Advances and Their Diffusion. Washington DC: The Brookings Institution, 1979.
2 Knaus WA, Thibault GE. Intensive care units today. In: McNeil BJ, Cravalho EG (Eds.). Critical Issues in Medical Technology. Boston: Auburn House Publishing Company 1982; 193-215.

3 Girotti MJ, Brown SJL. Reducing the costs of ICU admissions in Canada without diagnosis-related or case-mix groupings. Can Anaesth Soc J 1986; 33: 765-71.

4 Klem SA, Pollack MM, Getson PR. Cost, resource utilization, and severity of illness in intensive care. $J$ Pediatr 1990; 116: 231-7.

5 Ridley S, Biggam M, Stone P. Cost of intensive therapy. A description of methodology and initial results. Anaesthesia 1991; 46: 523-30.

6 Slayter MA, James OF, Moore PG, Leeder SR. Costs, severity of illness and outcome in intensive care. Anaesth Intensive Care 1986; 14: 381-9.

7 Byrick RJ, Mindorff C, McKee L, Mudge B. Costeffectiveness of intensive care for respiratory failure patients. Crit Care Med 1980; 8: 332-7.

8 Civetta $J M$, Hudson-Civetta $J A$. Maintaining quality of care while reducing charges in the ICU. Ann Surg 1985; 202: 524-30.

9 Gilbertson AA, Smith JM, Mostafa SM. The cost of an intensive care unit: a prospective study. Intensive Care Med 1991; 17: 204-8.

10 Oye RK, Bellamy PE. Patterns of resource consumption in medical intensive care. Chest 1991; 99: 685-9.

11 Detsky AS, Stricker SC, Mulley AG, Thibauit GE. Prognosis, survival, and the expenditure of hospital resources for patients in an intensive care unit. $\mathrm{N}$ Eng $\mathrm{J}$ Med 1981; 305: 667-72.

12 Lemeshow S, Teres D, Klar J, Avruni JS, Gehlbach SH, Rapoport $J$. Mortality probability models (MPM II) based 
on an international cohort of intensive care unit patients. JAMA 1993; 270: 2478-86.

13 Cullen DJ, Keene R, Waternaux C, Kunsman JM, Caldera $D L$, Peterson $H$. Results, charges, and benefits of intensive care for critically ill patients: update 1983. Crit Care Med 1984; 12: 102-6.

14 Wagner DP, Wineland TD, Knaus WA. The hidden costs of treating severely ill patients: charges and resource consumption in an intensive care unit. Health Care Financing Review 1983; 5: 81-6.

15 Nichols $D$. Developing actual costs of patient services: the University of Alberta Hospitals. Journal of Ambulatory Care Management 1993; 16: 61-8.

16 Norusis MJ. SPSS for Windows. Chicago, Illinois: SPSS Institute, 1993. 